\title{
GLYCOSIDES FROM LINARIA VULGARIS MILL
}

\author{
Natalia Mashcenko ${ }^{1 *}$, Pavel Kintia ${ }^{1}$, Angela Gurev ${ }^{1}$, Alexandra Marchenko ${ }^{1}$, \\ Carla Bassarello², Sonia Piacente ${ }^{2}$, Cosimo Pizza ${ }^{2}$ \\ ${ }^{1}$ Institute of Genetics and Plant Physiology, Academy of Sciences of the Republic Moldova, \\ Padurii str. 20, 2002, Chişinău, Moldova. \\ *mascenconnatalia@mail.ru, tel. 37322 555259, fax 37322556180 \\ ${ }^{2}$ Dipartimento di Scienze Farmaceutiche, Universita degli Studi di Salerno, Salerno, Italy
}

\begin{abstract}
A new flavonol glycoside, 5,4'-dimethylkaempferol 3-O- $\beta$-D-(6"- $\alpha$-L-rhamnopyranosyl)-glucopyranoside, together with three known compounds were isolated from the n-butanolic soluble fraction of underground and aerial parts of Linaria vulgaris Mill, collected on the territory of Moldova. The characterisation of these compounds was achieved by various chromatographic and spectroscopic methods (IR, UV, ${ }^{13} \mathrm{C}-\mathrm{NMR},{ }^{1} \mathrm{H}-\mathrm{NMR}$ and $\mathrm{MS}$ ).
\end{abstract}

Keywords: Linaria vulgaris Mill; flavonol glycoside; linaroside V; NMR analysis.

\section{Introduction}

Linaria vulgaris Mill is widely spread on the territory of Europe as well as in the Republic of Moldova. The plant is used in traditional, folk medicine and in homeopathy due to its contents of biologically active substances. In medicine, the liquid extract of $L$. vulgaris Mill is used as purgative [1], diuretic, stimulator of the gall-bladder secretion $[2,3]$. The ointment made from it is useful in the case of skin disease [1], while the tinctures in dentistry [4]. This plant has antibacterial and fungicidal properties and it is used for treating liver and kidney diseases, tonsillitis, asthma, dermatomes, etc [5].

The previous phytochemical investigation of $L$. vulgaris Mill has been revealed the presence of alkaloids, flavonoids, triterpenoids, steroids and iridoid glycosides [6 - 13].

A new compound IV and three known compounds I-III have been isolated from the butanol watery extract of the plants of $L$. vulgaris Mill. By comparison of physical and spectroscopic properties (m.p., IR, UV, ${ }^{1} \mathrm{H}-\mathrm{NMR},{ }^{13} \mathrm{C}-\mathrm{NMR}$ spectra), the known compounds were identified as antyrrinoside (I) [9], benzyl alcohol O- $\beta$-D-glycopyranoside (II) [14] and benzyl alcohol $\beta$-D-(2'-O- $\beta$-xylopyranosiyl)-glycopyranoside (III) $[15,16]$. In this article, we present the isolation and structural determination of the new compound, called linaroside $\mathrm{V}$, and give its ${ }^{13} \mathrm{C}$ - and ${ }^{1} \mathrm{H}-\mathrm{NMR}$ data, which have not been reported previously.

\section{Results and Discussion}

The n-butanol soluble fractions of L. vulgaris were fractionated on $\mathrm{SiO}_{2}$ columns. Further separation and purification was achieved by combining chromatographic methods (silica columns, Sephadex LH-20, HPLC) to yield compounds I-IV in a pure form.

Compound IV, named linaroside V, was obtained as yellow amorphous powder (m.p. 188-193 ${ }^{\circ} \mathrm{C}$ ). The ESMS spectroscopy of $\mathbf{I V}$ resulted in the quasimolecular ion $[\mathrm{M}+\mathrm{H}]^{+}$at $\mathrm{m} / \mathrm{z} 623$, indicating the molecular formula of $\mathrm{C}_{29} \mathrm{H}_{34} \mathrm{O}_{15}$. The IR spectrum showed strong absorption bands at 3420 (-OH group), 2965 (C-H bonds), 1650 ( $\mathrm{C}=\mathrm{C}$ aromatic ring), and $1620 \mathrm{~cm}^{-1}(\mathrm{C}=\mathrm{O})$, confirming the flavonoid nature of $\mathbf{I V}$. The structure of linaroside $\mathrm{V}$ was elucidated by ${ }^{13} \mathrm{C}-\mathrm{NMR}$ and ${ }^{1} \mathrm{H}$-NMR spectroscopy (see Table 1 ). The ${ }^{13} \mathrm{C}$ - and ${ }^{1} \mathrm{H}$-NMR spectra showed signals for aromatic ring at $\delta \mathrm{C} 122.5$ $128.4 \mathrm{ppm}$ and $\delta \mathrm{H} 6.92-7.15 \mathrm{ppm}$, while the signals at $\delta \mathrm{C} 60.0 ; 55.3 \mathrm{ppm}$ and $\delta \mathrm{H} 3.76 ; 3.85 \mathrm{ppm}$ indicated two methoxy substitutions in the aglycone. The ${ }^{1} \mathrm{H}-\mathrm{NMR}$ spectrum suggested that $\mathbf{I V}$ is a disaccharide on the basis of two signals in the sugar region at $\delta 5.12(\mathrm{~d}, \mathrm{~J}=7.1 \mathrm{~Hz})$ and $4.56 \mathrm{ppm}(\mathrm{s})$, corresponding to the anomeric proton of $\beta$-glucose and to the anomeric proton of the $\alpha$-rhamnose, respectively (rhamnose methyl group generates bonds at $\delta$ 17.7 in ${ }^{13} \mathrm{C}$-NMR and $1.05 \mathrm{ppm}$ in ${ }^{1} \mathrm{H}$-NMR). The $\alpha$-rhamnose was concluded to be attached to C- 6 of $\beta$-glucose moiety, which was confirmed by its ${ }^{13} \mathrm{C}-\mathrm{NMR}$ spectrum and ${ }^{1} \mathrm{H}-{ }^{1} \mathrm{H}$ COSY experiment. The $\mathrm{HMBC}$ spectra showed a correlation between the H-1'"-rhamnosyl proton $(\delta 4.56)$ and C-6" glucose unit (66.8 ppm), H-1"glucosyl proton at $\delta 5.12$ and aglycone C-3 ( $\delta 142.4 \mathrm{ppm})$. The findings defined the disaccharide as a 3-O-rutinoside [17].

The ${ }^{13} \mathrm{C}$ - and ${ }^{1} \mathrm{H}$-NMR spectral dates of IV have been compared with those previously described in the literature for nicotiflorin (kaempferol 3-O- $\beta$-D-(6"- $\alpha$-L-rhamnopyranosyl)-glucopyranoside) $[17,18]$. The coincidence of signals of the sugar moieties has been revealed, except for the signals corresponding to the flavonol aglycone, due to the presence of two methyl groups in the spectra of IV (Table 1). Different NMR experiments indicated C-5 and $\mathrm{C}-4^{\prime}$ methoxy substitutions in the aglycone. In $\mathrm{HMBC}$ experiment, the protons signals at $\delta 3.76\left(3 \mathrm{H}, \mathrm{OCH}_{3}\right)$ and 3.85 $\left(3 \mathrm{H}, \mathrm{OCH}_{3}\right)$ were correlated, with $\mathrm{C}-5$ at 132.2 and $\mathrm{C}-4^{\prime}$ at $162.5 \mathrm{ppm}$, respectively. Thus, the aglycone of $\mathbf{~ I V}$ is 5 , 4'-dimethylkaempferol. Considering all the data, the structure of the new flavonol glycoside - linaroside $\mathrm{V}$ is determined to be the 5, 4'-dimethylkaempferol 3-O- $\beta$-D-(6"- $\alpha$-L-rhamnopyranosyl)-glucopyranoside (Fig.1). 
The spectral data of compounds I-III, including UV, ${ }^{13} \mathrm{C}$ - and ${ }^{1} \mathrm{H}-\mathrm{NMR}$, were verified by comparison with those previously described in the literature $[9,14,15,16]$.

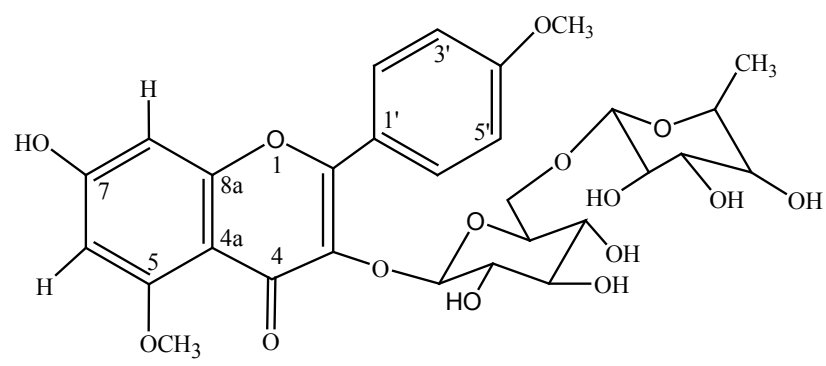

Fig. 1. Structure of linaroside V

${ }^{13} \mathrm{C}$ - and ${ }^{1} \mathrm{H}$ - NMR spectral data for compound IV (175 MHz, $300 \mathrm{MHz}, \mathrm{CD}_{3} \mathrm{OD}$, DMSO-d $)$

\begin{tabular}{|c|c|c|}
\hline Position & $\delta \mathrm{C}, \mathrm{ppm}$ & $\delta \mathrm{H}, \mathrm{ppm}, \mathrm{J}(\mathrm{Hz})$ \\
\hline \multicolumn{3}{|l|}{ Aglycon } \\
\hline 2 & 161.8 & \\
\hline 3 & 142.4 & \\
\hline 4 & 182.7 & \\
\hline 5 & 132.2 & \\
\hline 6 & 102.1 & $6.92 \mathrm{~d}(2.0)$ \\
\hline 7 & 152.2 & \\
\hline 8 & 94.0 & $6.93 \mathrm{~d}(2.5)$ \\
\hline 9 & 156.7 & \\
\hline 10 & 105.9 & \\
\hline $1^{\prime}$ & 122.5 & \\
\hline $2^{\prime}$ & 128.4 & $8.03 \mathrm{~d}(8.8)$ \\
\hline $3^{\prime}$ & 114.5 & $7.15 \mathrm{~d}(8.2)$ \\
\hline $4^{\prime}$ & 162.5 & \\
\hline $5^{\prime}$ & 114.5 & $7.15 \mathrm{~d}(8.4)$ \\
\hline $6^{\prime}$ & 128.4 & $8.03 \mathrm{~d}(8.6)$ \\
\hline \multicolumn{3}{|l|}{ Glc } \\
\hline $1^{\prime \prime}$ & 100.1 & $5.12 \mathrm{~d}(7.1)$ \\
\hline $2^{\prime \prime}$ & 73.1 & $3.33 \mathrm{~m}$ \\
\hline $3^{\prime \prime}$ & 76.3 & $3.32 \mathrm{~m}$ \\
\hline $4 "$ & 69.5 & $3.18 \mathrm{t}(8.6)$ \\
\hline $5 "$ & 75.5 & $3.62 \mathrm{~m}$ \\
\hline \multirow[t]{2}{*}{$6^{\prime \prime}$} & 66.8 & $3.47 \mathrm{~d}(10.8)$ \\
\hline & & $3.89 \mathrm{dd}(6 ; 9)$ \\
\hline \multicolumn{3}{|l|}{ Rha } \\
\hline $1^{\prime \prime \prime}$ & 100.3 & $4.56 \mathrm{~s}$ \\
\hline $2^{\prime \prime \prime}$ & 70.3 & $3.66 \mathrm{~m}$ \\
\hline $3^{\prime \prime \prime}$ & 70.7 & $3.46 \mathrm{~m}$ \\
\hline $4^{\prime \prime \prime}$ & 71.9 & $3.14 \mathrm{~m}$ \\
\hline $5^{\prime \prime \prime}$ & 68.5 & $3.41 \mathrm{~m}$ \\
\hline $6^{\prime \prime \prime}$ & 17.7 & $1,05 \mathrm{~d}(6.5)$ \\
\hline $\mathrm{MeO}-\mathrm{C}_{5}$ & 60 & $3.76 \mathrm{~s}$ \\
\hline $\mathrm{MeO}-\mathrm{C}_{4^{\prime}}$ & 55.3 & $3.85 \mathrm{~s}$ \\
\hline
\end{tabular}




\section{Conclusion}

The new flavonol glycoside called linaroside $\mathrm{V}$ has been isolated from Linaria vulgaris Mill and its chemical structure has been established by various spectroscopic methods.

\section{Experimental}

Plant material

The plants of Linaria vulgaris Mill were collected in the Rebublic of Moldova in august-september 2006 and were identified by Professor Vasilii Florea (Laboratory of Medicinal Plants, Academy of Sciences of Moldova).

\section{General Experimental Procedures}

Spectra were recorded using the following instruments: IR - on Specord 71-IR spectrophotometer, KBr; UV - on Specord UV-VIS spectrophotometer $(\mathrm{MeOH}, \mathrm{c}=1)$. ${ }^{1} \mathrm{H}-\mathrm{NMR}$ and ${ }^{13} \mathrm{C}-\mathrm{NMR}$ spectra were recorded on a Bruker DRX-spectrometer $(300 \mathrm{MHz}, 175 \mathrm{MHz})$; solvents $\mathrm{CD}_{3} \mathrm{OD}$, DMSO-d ; TMS as internal standard. The mass-spectra were obtained on ESMS in the positive ion mode instrument. The chromatography was performed on silica gel (60-100 $\mu \mathrm{m}$ Merck); GPC: Sephadex LH-20 (Pharmacia). Preparative HPLC: Varian ProStar 210, Varian 350 refractive index detector, Luna C-18 Phenomenex column $250 \mathrm{~cm}$ x $10 \mathrm{~mm}$ i.d. x $10 \mu \mathrm{m}, 50 \% \mathrm{MeOH}, 2.0 \mathrm{ml} \mathrm{min}^{-1}$.

\section{Extraction and Isolation}

The air-dried plants $(2 \mathrm{~kg})$ were extracted with $70 \%$ ethanol under reflux $(41 \times 3)$ for $5 \mathrm{~h}$ each time. The total extract was concentrated and extracted with $\mathrm{CHCl}_{3}$ and $\mathrm{n}-\mathrm{BuOH}$. The $\mathrm{n}-\mathrm{BuOH}$ soluble fraction was dried in vacuum (to afford $50 \mathrm{~g})$, purified by crystallization and fractionated by combining chromatographic methods: columns $(60 \mathrm{~mm} \times 30$ $\mathrm{mm})$ on silica gel $\left(40 \times 100 \mu \mathrm{m}\right.$, Merk) with a solvent system of $\mathrm{CHCl}_{3}-\mathrm{MeOH}_{2} \mathrm{O}(95: 5: 0 \rightarrow 300: 120: 30 \mathrm{v} / \mathrm{v} / \mathrm{v})$, and Sephadex LH-20 using MeOH. The fractions $(5 \mathrm{ml})$ were collected, characterized by TLC on Silufol. The fractions with similar $\mathrm{R}_{\mathrm{f}}$ values were recombined and further purified by reversed-phase HPLC. Four compounds (I-IV) were obtained: I -50 mg; II - $25 \mathrm{mg}$; III - $27 \mathrm{mg}$; IV - $120 \mathrm{mg}$.

Linaroside (IV) - yellow amorphous powder, m.p. 188-193 ${ }^{\circ} \mathrm{C}, \mathrm{R}_{\mathrm{f}}=0.54\left(\mathrm{CHCl}_{3}-\mathrm{MeOH}_{-} \mathrm{H}_{2} \mathrm{O} ; 76: 14: 3\right) ; \mathrm{IR}, v_{\max } \mathrm{KBr}$ $\mathrm{cm}^{-1}: 3420(\mathrm{oh}) ; 2695(\mathrm{C}-\mathrm{H}) ; 1650(\mathrm{C}=\mathrm{C}) ; 1620(\mathrm{C}=\mathrm{O})$. ESMS, m/z $623\left(\right.$ calcd for $\left.\mathrm{C}_{29} \mathrm{H}_{34} \mathrm{O}_{15}[\mathrm{M}+\mathrm{H}]^{+}\right) ; 476[\mathrm{M}+\mathrm{H}-\mathrm{Rha}]^{+}$; $314[\mathrm{M}+\mathrm{H}-\mathrm{Rha}-\mathrm{Glc}]]^{+} .{ }^{13} \mathrm{C}$ - and ${ }^{1} \mathrm{H}-\mathrm{NMR}$ see in the Table 1.

\section{Acknowledgments}

The authors are grateful to Irina Lunga the Institute of Genetics and Plant Physiology, for the preparation of linaroside V by HPLC.

\section{References}

[1]. Lesnikov, E.P. Phytoncides, Kiev, 1972, pp.126 - 128.

[2]. Gubanov, I.A.; Crilova, I.L.; Tihonova, V.I. Dicorastushchie rastenia SSSR, M., 1976, p. 360.

[3] Lecarstvennie rastenia: Rastenia-tseliteli, 3 izd., M., 1983, p. 400.

[3]. Marcenko, A.I.; Baraniuk, A.I.; Levitscaia, E.V.; Socolovskaia, E.P. Lecarstvennie rastenia v stomatologhii, Chishinev, 1981, p. 197.

[4]. Nasirov, X.M.; Zarudii, F.A. Sovremennie problemi farmacologhii, Kiev, 1971, pp. 196-197.

[5]. Menshikov, G.P.; Banikovskii, A.I.; Frolova, V.I.; Zhur. Obshei Khim., 1959, 29, p. 3846.

[6]. Morita, N.; Shimizu, M.; Arisawa, N.; Kobayashi, K. Yakugaku Zasshi, 1974, 94, pp. 913-916.

[7]. Hua, H.M.; Sun, J.; Li, X.; Chin. Trad. Herbal Drugs, 1999, 30, pp. 332-334.

[8]. Sticher, O. Phytochemistry, 1971, 10, pp. 1974-75.

[9]. Ilieva, E.I.; Handjieva, N.V.; Popov, S,.S. Phytochemistry, 1992, 31, pp. 1040-1041.

[10]. Ilieva, E.I.; Handjieva, N.V.; Spassov, S.; Popov, S.S. Phytochemistry, 1993, 32, pp. 1068-1070.

[11]. Hua, H.M.; Li, X.; Zhang, H.Q. J. Shenyang Pharm. Univ., 2000, 17, pp. 40-42, 48.

[12]. Hua, H.M.; Hou, B.L.; Li, W.; Li, X.; Zhang, Y. Chin. Trad. Herbal Drugs, 2000, 31, pp. 409-412.

[13]. Miyase, T.; Ueno, A.; Takizawa, N. Chem. Pharm. Bull., 1987, 35, pp. 1109-1117.

[14]. Sudo, H.; Ide, T.; Otsuka, H.; Hirata, E.; Takushi, A.; Shinzato, T; Takeda, J. Chem. Pharm. Bull., 2000, 48, pp. 542-546.

[15]. Kamel, M.; Mohamed, K.M.; Hassanean, H.A.; Ohtani, K.; Kasai, R.; Jamasaki, K. Phytochemistry, 2000, 55, pp. 353-357.

[16]. Tomczyk, M.; Gudej, J.; Sochacki, M. Z. Naturforsch, 2002, 57, pp. 440-444.

[17]. Bin, W.; Tsukasa, T.; Takehiro, K.; Shin-ichi, T. Chem.Pharm.Bull., 2007, 55, pp. 815-816. 